Each issue will contain several articles selected by a Guest Editor on a major health problem.

\title{
Introduction to Coronary Heart Disease Prevention Forum
}

\author{
Frederick H. EPSTEIN \\ Professor of Epidemiology, \\ School of Public Health, and \\ Director, Center for Research in Diseases of the Heart, \\ University of Michigan.
}

A prerequisite for preventing a disease is the ability to identify populations and individuals within the population especially susceptible to its development. Epidemiological studies during the past 10 or 20 years, in conjunction with clinical and experimental investigations, have placed coronary heart disease into the frontline of those disorders which can be predicted with a considerable degree of reliance well ahead of the onset of overt clinical manifestations. Thus, susceptibility toward this foremost consequence and complication of atherosclerotic disease can be defined so that groups and people selectively prone to this illness can be detected and, given preventive measures, protected.

In these terms, a strategy for prevention involves necessarily two parallel but intersecting avenues of attack: (1) a policy of prevention, aimed at the population at large, toward the modification of those "all-pervading" environmental factors which are responsible for the overall burden presented by coronary disease in so-called developed countries, (2) a policy of massdetection aimed at identifying individuals within the population who are at especially high risk. The first approach necessitates major decisions on a national level which are concerned with changes in the mode of life, such as nutritional habits. The second approach calls for extensive and effective facilities to screen large numbers of people for the presence of what are now generally called "risk factors." The present forum does not concern itself specifically with these broad policy questions which are now before the public and voluntary health agencies for discussion and, indeed, action. However, it is well to remember that the total community problem of coronary heart disease (CHD) cannot be solved except within the context of such broad and forceful nation-wide action. In the meantime, the practicing physician to whom this Journal and, therefore, this forum addresses itself will have to do what he can to detect and protect susceptibles among his patients and "prepatients" who come within his reach. The contributors to this 
Symposium hope that they have provided practically useful guidelines toward these ends.

In this forum, the general focus is on the individual. However, the individual cannot be separated from his family. Children acquire their parents' genes as well as their attitudes and habits. Identification of susceptibility in a parent must, therefore, immediately call attention to his or her children or parental siblings; the converse is equally true. Hence, prevention, especially early prevention, is an intrinsic part of "family medicine."

Prevention, in order to be rational and scientific, must forestall, halt or reverse the biological mechanisms causing the disease and must be based on demonstrating, by means of preventive trials, that intervention on environmental factors related to these mechanisms will, in fact, reduce the toll from the disease. Discussion of mechanisms and the field of preventive trials are beyond the confines of this forum; in this regard, reference is made to the literature (1-6).

Nutritional factors, smoking and physical indolence predispose to atherosclerosis and its consequences. The major emphasis in this forum is on guidelines for preventive action. At the same time, the contributors have taken pains to present some of the key scientific basis for such action. The first paper, on risk factors, addresses itself in part to the crucial issue whether their relation to coronary heart disease is one of cause-and-effect. A definitive answer to this question must come from the several controlled preventive trials which are now being conducted or in the process of planning $(4,5)$. For the purpose of this forum, however, it will be assumed that the evidence, though partly circumstantial at this point in time, is sufficiently compelling to warrant preventive measures along the lines recommended by the contributors. This position rests largely on the belief that measures which, on the basis of the best evidence available, have a fair chance to do good and are unlikely to do harm, cannot be reasonably withheld from people known to harbor a susceptibility toward coronary heart disease (7).

The second contribution, on nutrition, by Dr. and Mrs. Connor makes a strong case for the need to change eating habits in order to prevent atherosclerosis and its consequences. Their dietary prescription is aimed uncompromisingly at a maximal preventative effect. Those who would consider this optimal advice unnecessarily rigid must keep in mind that the authors recommend nutritional changes which are intended to eliminate coronary heart disease as a public health problem. The price paid for a more moderate course will, in all likelihood, be a more moderate reduction in the community burden of coronary heart disease. To some, this would appear preferable to dietary recommendations which could seem so forbidding and restrictive to a fair number of people that they might do nothing rather than make at least partially effective modifications in their eating habits. Dr. and Mrs. Connor's recommendations should be considered within the framework of such a balanced view, remembering that even those who would go less far will agree with their basic position. In fact, they themselves state: "For persons who cannot accept this maximal dietary approach, a diet which is still low in cholesterol and moderately low in fat may be used." Obviously, the higher a person's 
individual risk, the more imperative it is to follow the Connors' advice as closely as possible!

In comparison with the matter of diet, the position with regard to smoking might at first appear more straightforward. Professor Reid puts the current situation into perspective, pointing forthrightly to issues which still present problems, yet building up a strong and constructive case against the cigarette habit. The concluding paper gets away from the usual well-meant but all-toovague admonition to exercise more and regularly for the maintenance of good cardiovascular function. Dr. Fox deals in a practical way with the question: "How much exercise and what kind?", basing his advice on current knowledge from research in cardiology and physiology.

In closing, it must be kept in mind that control by means of changes related to nutrition, smoking, and "physical immobility" habits do not provide the only possible approaches to the prevention of coronary heart disease. They have been selected for inclusion in the forum either because they are considered to be of major etiological importance, most immediately (though not necessarily easily) amenable to change, or both. Other factors are likely to be involved (2,7-9). Hereditary predisposition or influences related to the social environment and psychosocial interactions are examples. Yet, while it is true that those genetically predisposed are in the greatest need to take care of their environment and although the relationships between psychic and sociocultural features enter the picture at several points, the present emphasis is on what is most readily within practical reach.

These issues have relevance not only to countries where coronary heart disease is currently a foremost health problem but those which develop greater affluence and its less desirable but not inevitable concomitant: the acquisition of living habits which, from all that is known or suspected, predispose to atherosclerosis. Such developing nations can still stem the tide by thoughtful, preventive public health policy. Developed countries, on the other hand, can reverse the tide through preventive action which should start early in life because the more advanced atherosclerotic lesions probably do not regress to any appreciable extent.

\section{REFERENCES}

1. Moses, C. "Atherosclerosis-Mechanisms as a Guide to Prevention." Lea and Febiger, Philadelphia, 1963.

2. Stamler, J. "Lectures on Preventive Cardiology." Grune and Stratton, Inc., N. Y., 1967.

3. The National Diet-Heart Study: Final Report by the National Diet-Heart Study Research Group. Circulation 37, No. 3, Suppl. No. 1, 1968.

4. Mass Field Trials of the Diet-Heart Question: Their significance, timeliness, feasibility and appreciability. Report of the Diet-Heart Review Panel of the National Heart Institute (E. H. Ahrens, Jr., Chairman). American Heart Association Monograph No. 28; 1969, New York, American Heart Association, Inc.

5. STAMLER, J. Acute myocardial infarction-progress in primary prevention. Brit. Heart J. 33 (Suppl.), 145 (1971).

6. The Primary Prevention of the Atherosclerotic Diseases: Position Paper for the Intersociety Commission for Heart Disease Resources prepared by the Atherosclerosis Study Group (J. Stamler, Chairman) and the Epidemiology Study Group (A. M. Lilienfeld, Chairman). Circulation 52, A55 (1970). 
7. EPSTEIN, F. H. Coronary heart disease epidemiology-Current aspects of research, prevention and community programs. in "Trends in Epidemiology, Community Health and Tropical Medicine" (Stewart, G. T., Ed.), Charles C Thomas, Springfield, Ill., (in press).

8. Epstein, F. H., AND Ostrander, L. D., Jr. Detection of individual susceptibility toward coronary disease. Prog. Cardiovasc. Dis. 13, 324 (1971).

9. STAMLER, J. AND EPSTEIN, F. H. Coronary heart disease: risk factors as guides to preventive action (this forum). 